\title{
FEASIBILITY OF THE APPLICATION OF BOREHOLE SEISMOLOGY FOR HARD ROCK EXPLORATION
}

\author{
Andrew Greenwood ${ }^{1}$, Milovan Urosevic ${ }^{2}$, Anton Kepic ${ }^{3}$ \\ Curtin University of Technology ${ }^{1,2,3}$, Andrew.Greenwood@postgrad.curtin.edu.au' ${ }^{\prime}$, \\ M.Urosevic@curtin.edu.au²,A.Kepic@curtin.edu.au ${ }^{3}$
}

Key Words: Mineral exploration, Hard rocks, Borehole seismology, Vertical Seismic Profiling.

\section{INTRODUCTION}

Mineralisation of economic importance typically occurs in hard rock environments that tests the resolution limits of surface seismic techniques. Complex geology, steeply dipping structures and thick highly heterogeneous regolith cover hinder collection, processing and interpretation of seismic data. Hard rock units in contact often exhibit similar elastic properties with small velocity and density contrasts. In addition, reactivated, altered and highly fractured zones cause significant scattering of seismic energy. All these factors can combine to make it very difficult to produce interpretable images from seismic reflection surveys. Borehole seismic methods reduce the effects of wavefield scattering by placing either the receiver or source within the bedrock. The result is higher signal to noise ratios, higher frequency content and greater accuracy in velocity observations, ultimately giving higher resolution images.

To test the viability of borehole seismology in typical hard rock exploration environments we have conducted a number of modelling tests. These tests are aimed to demonstrate the potential of recording and producing high resolution images from borehole seismic measurements. We also offer potential Vertical Seismic Profile (VSP) methodologies to assist in hard rock seismic exploration.

\section{MODELLING}

Full waveform modelling was undertaken using TesseralCS-2D modelling package. A fairly complex earth model was chosen; one which depicts real geology found in the Eastern Goldfields of Western Australia, and is shown in Figure 1. The model has an overburden (regolith) layer of variable depth, metavolcaniclastic host rock, with shallow to steep dipping mineralised shear zones, mafic intrusions and interbedded dolerite, and banded iron formations (BIF) (Newton et al. 1998). Hard rock seismic exploration in Western Australia is still in its juvenile stages, as such there is a lack of knowledge of typical seismic and sonic velocities. Seismic velocities assigned to the model were chosen using preset values for geological units within Tesseral, a typical value for regolith (Urosevic et al. 2005) and prior stacking velocities. To simulate a borehole VSP (2D) seismic survey, 46 source locations were used spaced $20 \mathrm{~m}$ along the surface and 500 receiver positions were assigned along the borehole at $1 \mathrm{~m}$ intervals. The borehole is typical of mineral exploration drilling. It is angled at approximately 60 degrees and aimed to orthogonally intersect the shear zone and common dip of the geology. Acoustic full-wave form modelling used Ricker wavelets of 40 and $80 \mathrm{~Hz}$ dominant frequencies with a sampling rate of $0.5 \mathrm{~ms}$ and record length of $250 \mathrm{~ms}$.

Processing of the synthetic seismic data was then completed using RadExPro Plus software (by DECO Geophysical). Acoustic modelling and processing was problematic with the low velocity variable regolith included; causing excessive reverberation and multiples in the data sets. Consequently, a pseudo 2D seismic section was constructed using trace mixing from two depth corrected data sets: a data set which included the problematic regolith and a second data set with the regolith removed through velocity replacement (as would happen if correct statics were applied). The replacement velocity used was that of the host rock $(5500 \mathrm{~m} / \mathrm{s})$. The resulting section is shown as Figure 2. 


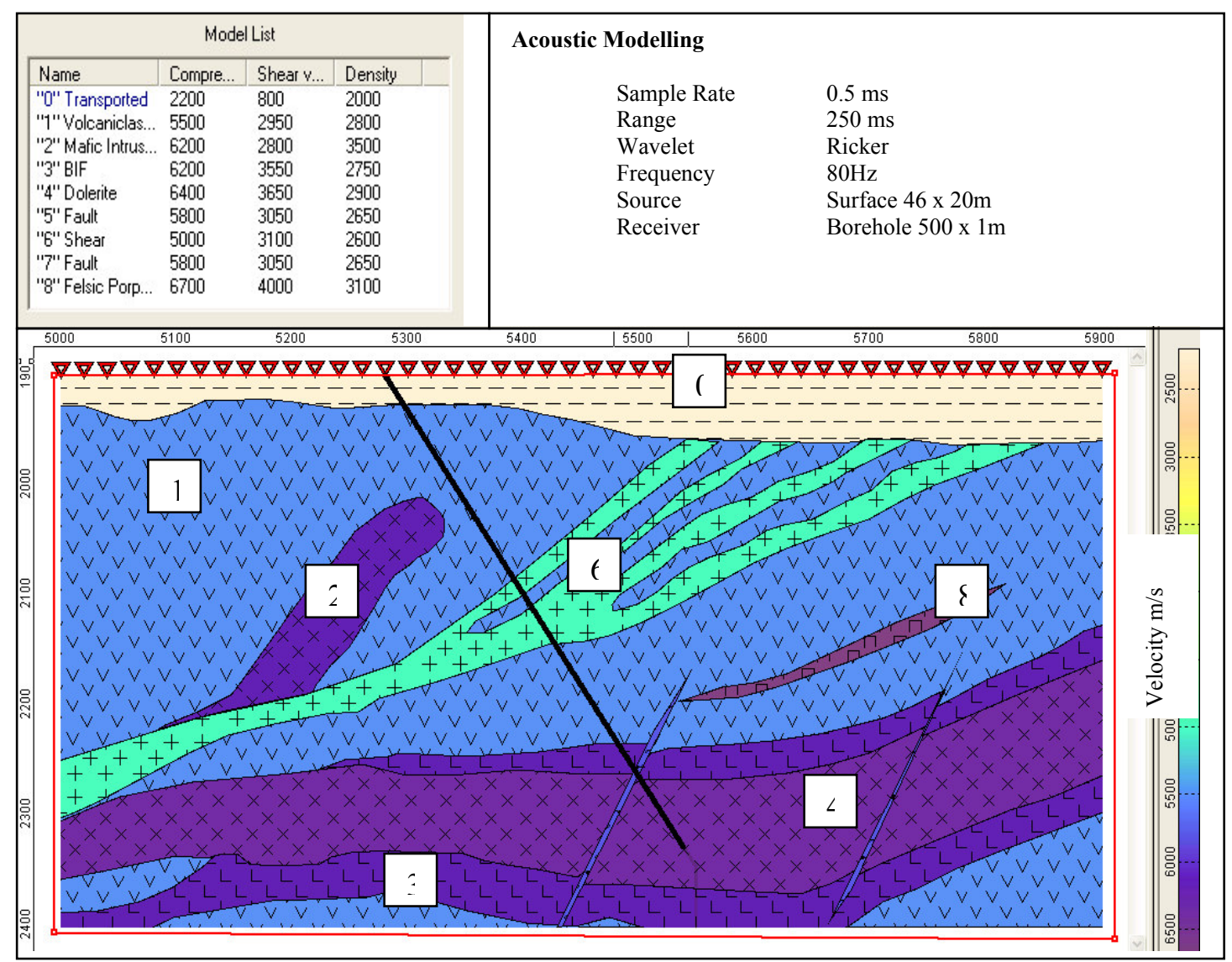

Figure 1: Geology model used to generate synthetic seismograms. Seismic velocities, source receiver geometry and acquisition parameters are in the table above. This model is complex, with shallow to steeply dipping shear and intrusive structures overlain by a variable depth slow velocity layer.

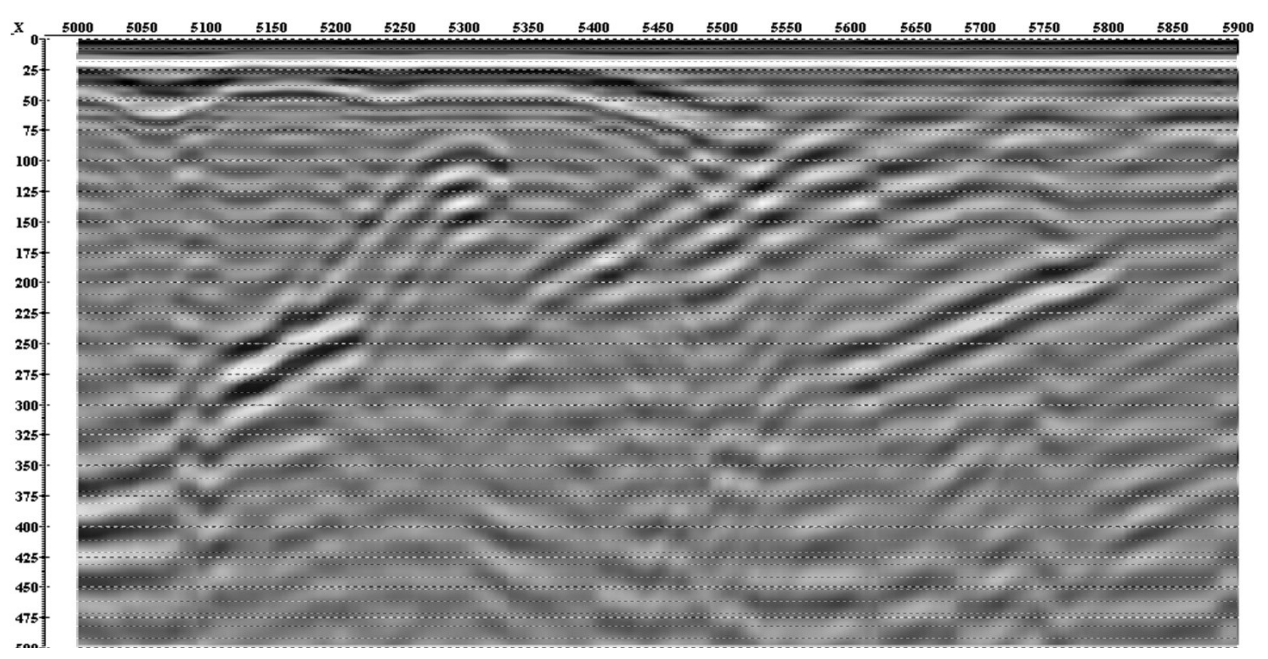

Figure 2: Pseudo seismic section produced from Vertical Incidence Modelling using an $80 \mathrm{~Hz}$ Ricker wavelet and Ims sample rate. The effects of low velocity and variable overburden have been reduced through trace mixing and substituting the regolith velocity $(2200 \mathrm{~m} / \mathrm{s})$ for host rock velocity across two data sets. Time to Depth conversion also used the host rock velocity of $5500 \mathrm{~m} / \mathrm{s}$.

Synthetic VSP shot records were produced for each source location and processed together to create a migrated image. Processing steps used were: Resample traces; first break picking; horizon flattening; 2D spatial filtering; removal of down going wave field; deconvolution; un-flatten horizon; band pass filtering and VSP Curved Kirchoff Migration (RadExPro Plus v3.8 Advanced feature). Synthetic data with and without the regolith layer present were processed. Figure 3 shows two Migrated VSP sections 
for a) $40 \mathrm{~Hz}$ wavelet and regolith removed and b) $80 \mathrm{~Hz}$ wavelet with regolith present. Section $\mathrm{b}$ required secondary and tertiary horizons to be picked for down-going multiple removal.

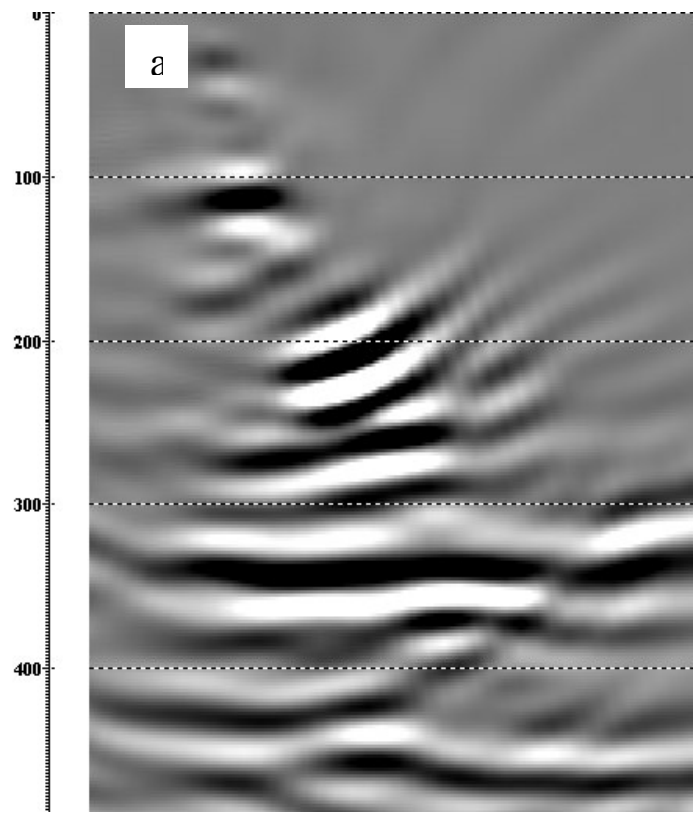

\section{t}

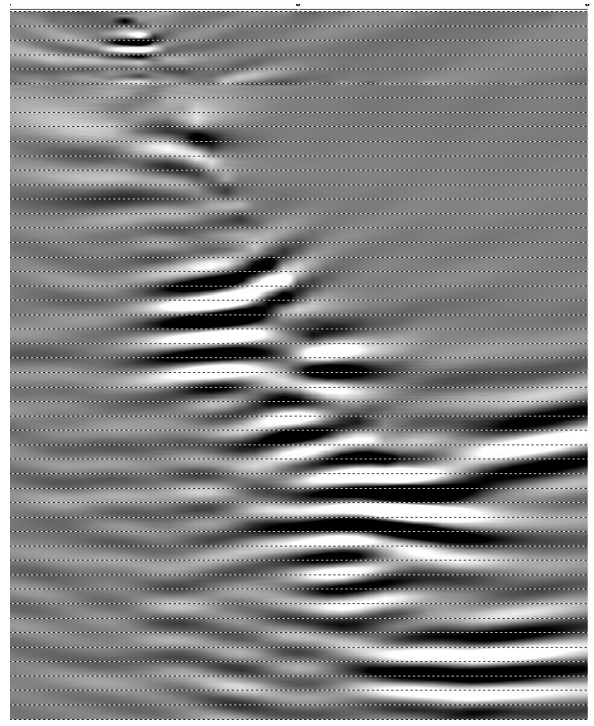

Figure 3: Migrated VSP sections a) 40Hz dominant frequency with simplified geology (regolith layer / host rock velocity substitution). b) $80 \mathrm{~Hz}$ dominant frequency, low velocity regolith present

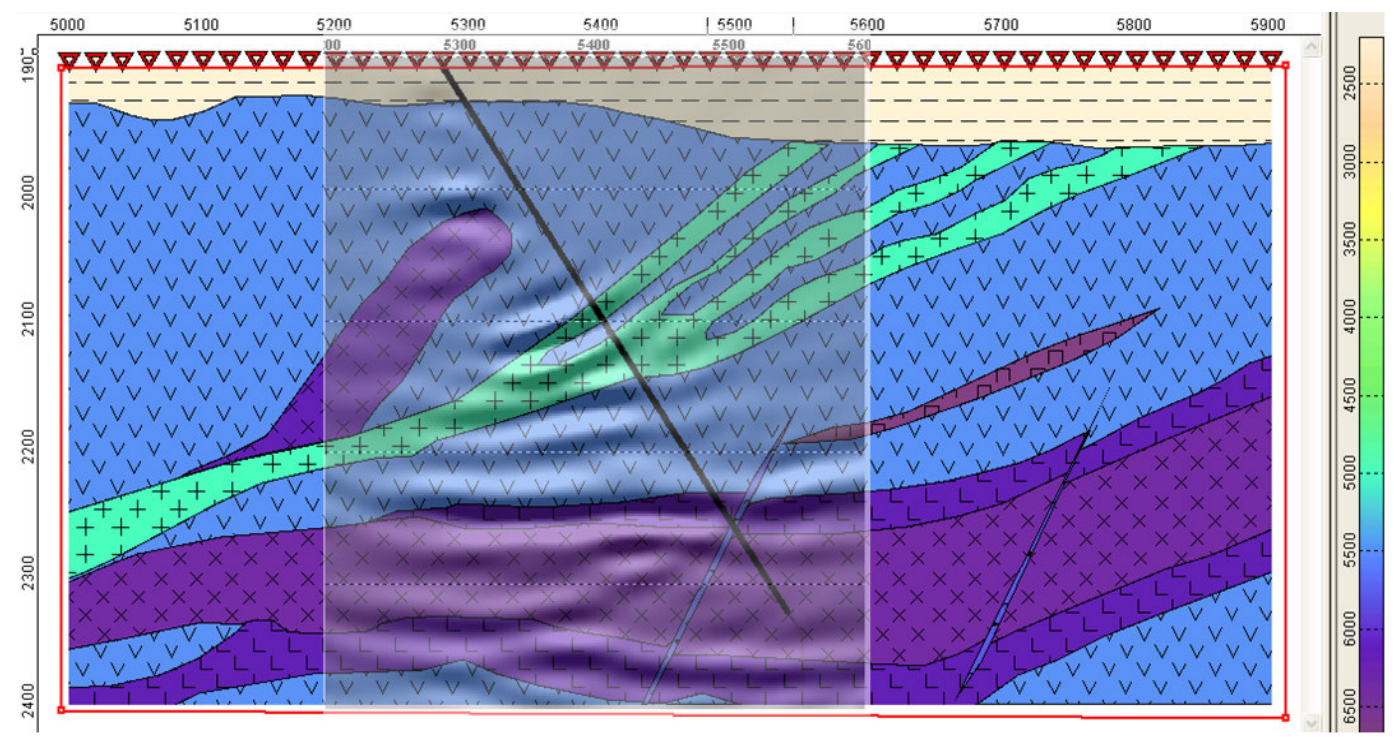

Figure 4: Migrated VSP section overlying the geologic model.

Both migrated sections correlate well with the geologic model. Section (a) has been overlaid the geological model in Figure 4. The $80 \mathrm{~Hz}$ section (b) is inherently of higher resolution than $40 \mathrm{~Hz}$ section (a). 


\section{DISCUSSION}

Through the use of Kirchoff depth migration it has been demonstrated that it is possible to image steeply dipping events well in complex environments with walk away VSP data in angled boreholes. Complex geological environments are not easily (seismically) modelled when a low velocity overburden is present. The effect of this overburden is detrimental to $2 \mathrm{D}$ surface profiles, creating significant multiples in the stacked sections. VSP is less affected by this problem due to the receivers being below this layer. The VSP images have higher resolution at depths where information is required compared to 2D surface sections. There is the potential to produce high resolution sections across many boreholes by stacking/merging migrated VSP sections together.

Borehole seismology in angled holes also offers the potential to use travel time tomography to delineate the base of regolith. This combined with simultaneous collection of $2 \mathrm{D}$ and $3 \mathrm{D}$ surface seismic could greatly improve the calculation of static corrections and assist velocity modelling. This idea is yet to be tested or developed, but our simulations show that such approaches will be needed to wring the most out VSP imaging.

Often the surface seismic response over shear zones has high reflectivity (Urosevic et al. 2007). This cannot be intuitively predicted from existing core sample measurements. One possibility is that the internal structure of a shear zone can produce an alignment in elastic properties. This would make shear zones anisotropic to seismic wave propagation and explain the characteristic signature (unusually high amplitudes) observed in surface seismic data.

To further the understanding of reflectivity and seismically characterise hard rock environments, insitu borehole measurements are required. Such imaging and characterisation with VSP will require different survey geometries such as targeted along dip holes. This will allow seismic characterisation within alteration and shear zones; thus, potentially illuminating larger structures not detectable at the micro scale of core sampling yet opaque to surface seismic. Further to this if 3 component (3C) sensors and primary $(\mathrm{P})$ and secondary $(\mathrm{S})$ wavefields are recorded then it will be possible to identify seismic anisotropy and characterise hard rocks elastically. This will be at the cost of having to collect higher fold data than is current practice used in surface seismic surveys.

\section{ACKNOWLEDGEMENT}

We are grateful to the Centre of Excellence for High Definition Geophysics at Curtin University of Technology for the financial support and implementation of research into hard rock borehole seismology. Thank you to Dr Roman Pevzner for the tuition and technical support with RadExPro software.

\section{REFERENCES}

Newton, P. G. N., Gibbs D., et al. 1998. "Sunrise-Cleo gold deposit." Monograph Series - Australasian Institute of Mining and Metallurgy 22: 179-186.

Urosevic, M., Kepic A., et al. 2007. Seismic exploration of ore deposits in Western Australia. Exploration 07, Toronto, Canada.

Urosevic, M., Stolz, E.et al. 2005. Seismic exploration for gold in a hard rock environment - Yilgarn Craton, Western Australia. 67th Meeting, EAGE. 